\title{
PADRONIZAÇÃO DA CITOLOGIA DE IMPRESSÃO DA SUPERFÍCIE OCULAR CANINA
}

\author{
(Standardization of canine ocular surface impression cytology) \\ GODOY-ESTEVES, C.A.L.; BARROS, J.N.2; CUNHA, L.S.; MASCARO, V.L.D.4; \\ HOFLING-LIMA, A.L. ${ }^{5}$; BARROS, P.S.M. ${ }^{6}$ \\ 1Pós-graduanda nível Doutorado, do Departamento de Cirurgia da FMVZ-USP- e-mail: cgodoy@usp.br ou \\ cintiagodoy@ig.com.br; \\ ${ }^{2}$ Tecnólogo Oftálmico do Departamento de Oftalmologia da UNIFESP: \\ ${ }^{3}$ Médica veterinária, colaboradora do Departamento de Cirurgia da FMVZ-USP; \\ ${ }^{4}$ Oftalmologista colaboradora do Laboratório de Doenças Externas Oculares e do setor de Patologias \\ Externas e Córnea, do Departamento de Oftalmologia da UNIFESP; \\ ${ }^{5}$ Livre-docente, chefe do Departamento de Oftalmologia da UNIFESP; \\ ${ }^{6}$ Prof. Titular do Departamento de Cirurgia da FMVZ-USP.
}

RESUMO - Técnica de exame de citologia de impressão foi padronizada em olhos de cães sem alterações oculares. Foram realizados exames de citologia de impressão do epitélio corneano, conjuntival e tarsal em 30 olhos de 21 animais de raças e idades variadas. As amostras foram colhidas de cães atendidos no Hospital Veterinário da FMVZ-USP entre fevereiro e julho de 2003, sendo coradas e avaliadas no Laboratório de Doenças Externas Oculares da UNIFESP. A colheita foi bem tolerada pelos cães e o papel filtro utilizado removeu células em quantidade e morfologia adequadas para estudo citológico. Foi observado em 100\% dos casos que o epitélio da conjuntiva bulbar canina apresenta aspecto "metaplasia-like", com ausência de células caliciformes. Estas só foram encontradas na conjuntiva tarsal em $21,4 \%$ das amostras avaliadas dessa região. A citologia de impressão é um método factível para avaliação da superfície ocular em cães. Entretanto, a celularidade das amostras obtidas do tarso mostrou-se inadequada. Além disso, a pesquisa da densidade de células caliciformes em áreas bulbares, embora usada em seres humanos, pode não servir como indicador de alteração da superfície ocular para a espécie canina.

Palavras-chave: Citologia de impressão, Superfície ocular, Cães, Células caliciformes, Metaplasia.

ABSTRACT - Impression cytology technique in dog eyes without ocular disease was standardized. Impression cytology was performed in corneal, conjunctival and tarsal epithelium in 30 eyes of 21 animals with different races and ages. Samples were obtained from dogs attended in FMVZ-USP Veterinary Hospital between February to July 2003, being stained and evaluated at UNIFESP's External Eye Disease Laboratory. Sampling was well tolerated by dogs and the filter paper used removed cells with adequate morphology and quantity for cytologyc evaluation. In all cases canine bulbar conjunctival epithelium showed metaplasia-like features without goblet cells. Impression cytology is a feasible method for ocular surface evaluation in dogs. However, celularity was considered inadequated in samples obtained from tarsal conjunctiva. Furthermore, seeking goblet cell density in bulbar areas, although used in human beings, may not be used as an ocular surface disease indicator in canine species.

Key-words: Impression cytology; Ocular surface; Dogs; Goblet cells; Metaplasia. 


\section{Introdução}

A citologia de impressão, técnica de biópsia não invasiva para avaliação do epitélio da superfície ocular, emprega uso de papel filtro de ésteres de celulose e foi introduzida por EGBERT et al., 1977. Este, após experiências com diferentes materiais, verificou que os filtros da Millipore forneciam os melhores resultados na aquisição de amostras da camada epitelial superficial obtida por pressão do papel filtro sobre a superfície ocular (EGBERT et al., 1977). Modificada por vários autores (TSENG, 1985; NELSON,1988; THIEL et al., 1997), a citologia de impressão tem sido adotada em estudos de diferentes doenças da superfície ocular. Por ser não invasiva e preservar não só as características morfológicas das células mas também a relação anatômica entre elas, a técnica representa uma alternativa à biópsia excisional, aos esfregaços conjuntivais realizados com espátulas e à citologia por escova (DART, 1997). A citologia de impressão foi utilizada para se testar a validade da técnica nas lesões oculares da conjuntiva palpebral do homem e do cão, com correlações dos achados nas duas espécies (ROCHA et al., 2002). Em estudo anterior, cães com ceratoconjuntivite seca foram submetidos ao uso de ciclosporina tópica e as características do epitélio conjuntival anteriores e posteriores ao tratamento foram avaliadas com a citologia de impressão, mas não houve um grupo controle (BOURNOUS et al., 1998). Recentemente, técnica de citologia conjuntival por impressão adaptada para o uso na espécie canina foi descrita (BOLZAN, 2003).

Apesar da existência de relatos sobre a utilização da citologia em cães e da variabilidade de técnicas (BOURNOUS et al., 1998; ROCHA et al., 2002; BOLZAN, 2003), não encontram-se referências que descrevam a padronização da citologia de impressão córneoconjuntival em cães com olhos sadios. Esse foi o objetivo do presente estudo.

\section{Material e Método}

Um total de 69 amostras (39 córneoconjuntivais e 30 da conjuntiva tarsal) da camada epitelial foram obtidas por citologia de impressão de 30 olhos de 21 cães de diferentes raças e idades que variaram de 3 meses a 13 anos. Em relação à raça, incluíram-se casos de cães poodle $(n=5)$, cocker $(n=3)$, yorkshire $(n=2)$, pastor alemão $(n=2)$, rotweiller $(n=2), S R D$ $(n=2)$, setter irlandês $(n=1)$, Ihasa apso $(n=1)$, pinscher $(n=1)$, doberman $(n=1)$ e bassethound $(n=1)$. Quanto ao sexo, $52 \%$ destes animais eram machos, $48 \%$ eram fêmeas e todos foram atendidos no Hospital Veterinário da FMVZ-USP, no período de fevereiro a julho de 2003. Os cães foram submetidos a exame oftalmológico e após confirmação da ausência de alterações oculares, foram incluídos no estudo. A exemplo dos locais possíveis de colheita em humanos (TSENG, 1985), obtiveram-se amostras das conjuntivas bulbar superior, bulbar temporal, tarsal superior, tarsal inferior e da córnea, do olho direito, do esquerdo ou de ambos. As tentativas de colheita das regiões nasal e inferior da conjuntiva bulbar mostraram-se inviáveis devido à presença da terceira pálpebra.

A camada epitelial para estudo pelo método de citologia de impressão foi obtida após anestesia tópica e aplicação sobre essas regiões de papel filtro de acetato de celulose esterilizado previamente em óxido de etileno. Cinco animais $(23,8 \%)$ estavam sob efeito de anestesia geral para a realização de procedimentos cirúrgicos não oculares. $O$ filtro da Millipore Corporation com poro de 0,45 micra (HAWP304F0 e HAWP04700), cortado manualmente com dimensões aproximadas de $5 \mathrm{~mm}$ de largura $\times 7 \mathrm{~mm}$ de altura, com ápice, base e abertura lateral foi posicionado com uma pinça de modo que a ponta do papel (ápice) ficasse sobre a córnea, a abertura no limbo e a base sobre a conjuntiva em colheitas córneoconjuntivais (FIGURA 1). Nas colheitas de amostras da conjuntiva tarsal, o papel foi aplicado na posição horizontal com base nasal e abertura para baixo ou base temporal e abertura para cima. Após pressão por 5 segundos, foi removido e imediatamente imerso em solução fixadora (ácido acético glacial, formaldeído a $37 \%$ e álcool etílico a $70 \%$, $1: 1: 20)$ e posteriormente corado com ácido periódico de Schiff (PAS), hematoxilina e Papanicolaou modificado, conforme técnica padronizada para seres humanos (MARTINEZ, et al., 1995; BARROS, et al., 2000; BARROS, et al.,2001). 


\section{FIGURA 1 - PAPEL FILTRO POSICIONADO NO OLHO DO CÃO. OBSERVAR ABERTURA LATERAL NO PAPEL POSICIONADANA REGIÃO DO LIMBO, BASE VOLTADA PARAA CONJUNTIVA BULBAR E ÁPICE SOBRE CÓRNEA.}

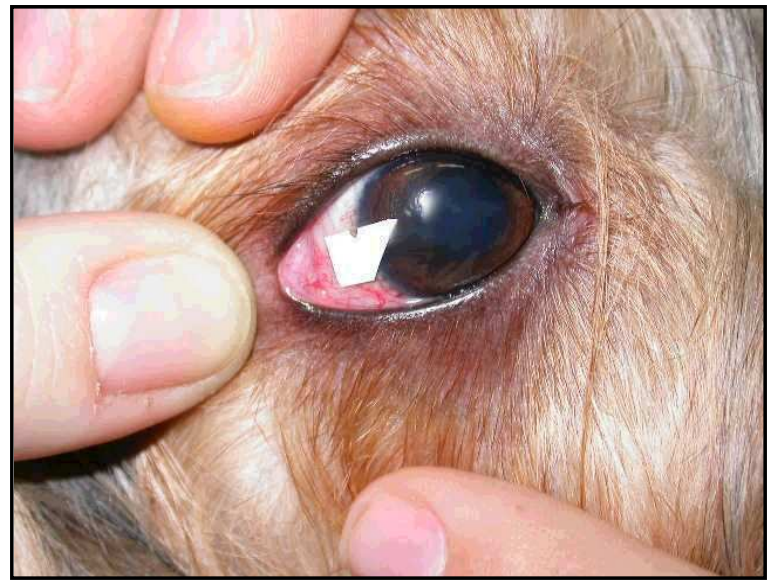

Cada amostra em papel filtro contendo células da superfície ocular foi analisada com microscópio óptico no Laboratório de Doenças Externas Oculares do Departamento de Oftalmologia da Universidade Federal de São Paulo - EPM. Foi considerada amostra adequada para inclusão no estudo, o filtro com pelo menos $1 / 3$ de sua superfície preenchida com células epiteliais. Ao microscópio, foram observados os seguintes detalhes citológicos: celularidade - número de células obtidas por colheita, morfologia - grau de preservação dos detalhes citológicos das células epiteliais, relação núcleo/citoplasma das células epiteliais, densidade de células caliciformes, presença de células inflamatórias, filamentos de muco, mucina, alterações nucleares ou citoplasmáticas e filamentos de secreção.

\section{Resultados}

A imagem observada nas lâminas apresentou qualidade para análise citológica em todo o grupo estudado. A celularidade correspondeu a pelo menos $1 / 3$ da área do papel filtro preenchido em todas as amostras córneo-conjuntivais e apenas em 14 das 30 provenientes da conjuntiva tarsal. Nessas últimas, observou-se a menor celularidade entre as regiões pesquisadas. A morfologia foi considerada adequada ou razoável em todas as amostras. As células epiteliais coraram-se basofilicamente, na maioria das vezes com núcleos pálidos. As células caliciformes coraram-se com PAS e o material de filamentos de muco num tom mais arroxeado, quando encontrados. As células observadas por este método aparecem predominantemente em uma única camada (FIGURA 2).

$\mathrm{Na}$ região superficial da córnea periférica adjacente ao limbo, superior e temporal, $(n=39)$, as amostras continham células epiteliais separadas com relação núcleo/ citoplasma (rel.N/C) 1:5 e bordas citoplasmáticas dobradas na maioria dos casos. Em apenas 7,7\%, observou-se pequeno feixe de células epiteliais com coesão intercelular. Não foram encontradas células caliciformes e mucina nesse local em $100 \%$ dos casos. Células inflamatórias e filamentos de muco não foram observados em $89,7 \%$ das amostras. Alterações nucleares foram detectadas em $46,1 \%$ do grupo e foram caracterizadas por palidez ou perda do núcleo, cariopicnose ou cariorrexe e, raramente, binucleação. 
FIGURA 2 - FOTOMICROGRAFIAS (PAS+HEMATOXILINA+PAPANICOLAOU)

A) CÉLULAS EPITELIAIS SEPARADAS OBTIDAS DA CÓRNEA PERIFÉRICA - ACHADO OBSERVADO EM 92,3\%, 400X

B) CÉLULAS EPITELIAIS COESAS OBTIDAS DA CÓRNEA - ACHADO DE APENAS 7,7\% DAS AMOSTRAS, 400X.

C) CÉLULAS EPITELIAIS COESAS OBTIDAS DA CONJUNTIVA BULBAR SUPERIOR ACHADO DE APENAS 12,8\% DOS CASOS, 400X.

D) FEIXE DE CÉLULAS EPITELIAIS COESAS COM CÉLULAS CALICIFORMES ÍNTEGRAS OBTIDOS DA CONJUNTIVA TARSAL, 400X

E) CÉLULAS EPITELIAIS SEPARADAS ANUCLEADAS E DEBRIS OBTIDOS DA CONJUNTIVA BULBAR TEMPORAL - PERDA DA COESÃO INTERCELULAR FOI O ACHADO MAIS FREQÜENTE NA CONJUNTIVA (87,2\%), SEGUIDO DA ALTERAÇÃO DO NÚCLEO (71,8\%), 200X.

F) CÉLULAS EPITELIAIS SEPARADAS ISOLADAS, MUCINA E CÉLULAS INFLAMATÓRIAS DO TIPO PMN OBTIDOS DA CONJUNTIVA TARSAL SUPERIOR, 400X.
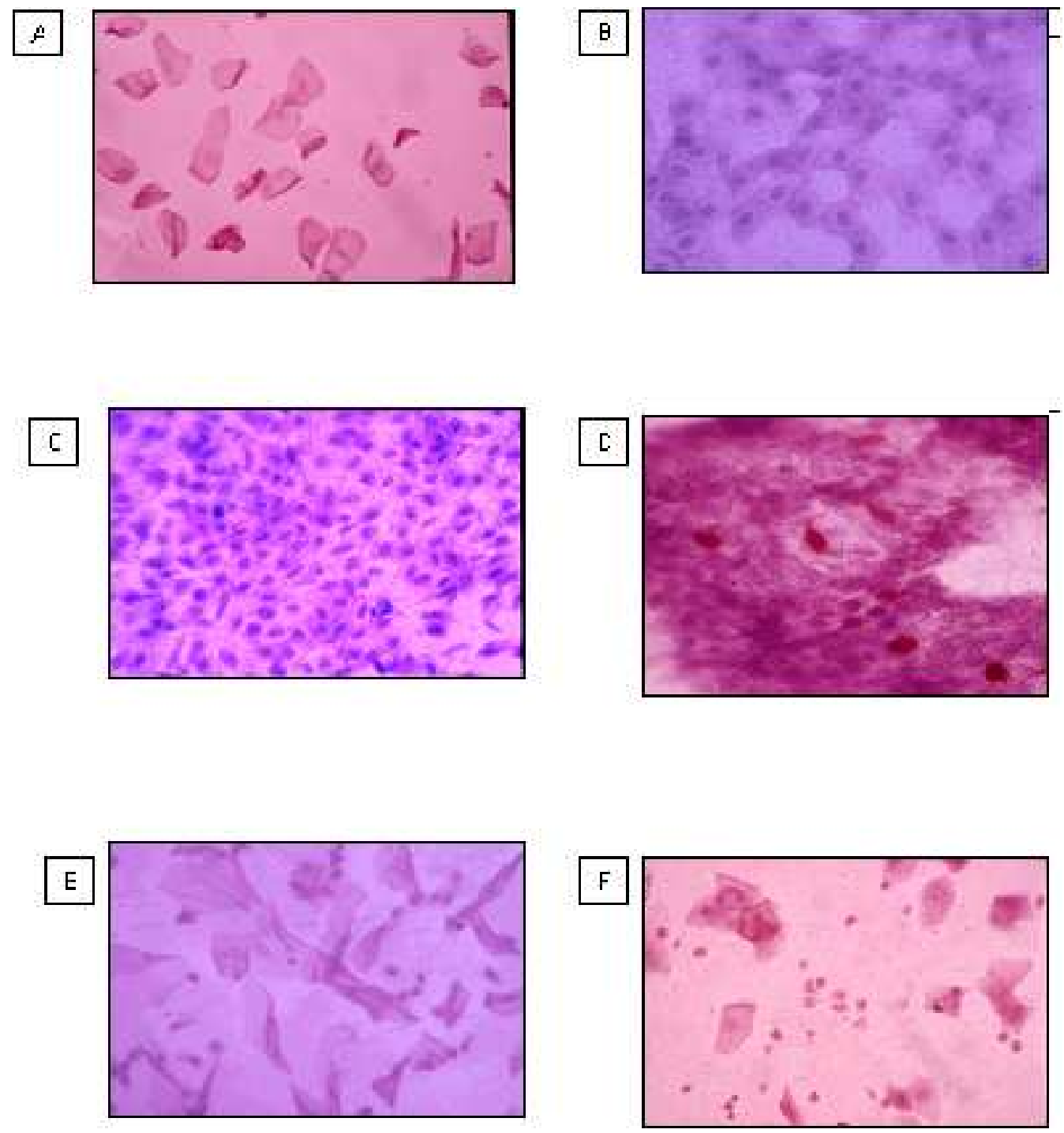
Na superfície da conjuntiva bulbar $(n=39)$, superior e temporal, as amostras continham células epiteliais separadas, bordas citoplasmáticas dobradas, mais alongadas e de rel. N/C variando de 1:2 a 1:7. Em apenas $12,8 \%$, pequenos feixes de células coesas foram observados. Não foram encontradas células caliciformes e mucina nesse local em $100 \%$ das amostras. Em $30,7 \%$ do grupo, filamentos de muco foram observados e em $50 \%$ destes havia também células inflamatórias (essencialmente neutrófilos). Mucina foi observada em $15,4 \%$ dos casos exclusivamente na base do papel, que coincidia com a região do fórnice. Alterações nucleares caracterizadas principalmente por anucleação e cariorrexe, e ocasionalmente por cariopicnose, binucleação e palidez foram observadas em $71,8 \%$ das amostras.

$\mathrm{Na}$ superfície do tarso, a qualidade da colheita foi analisada nas 30 amostras e em 14 $(47 \%)$ delas considerada adequada para leitura, isto é, com pelo menos $1 / 3$ da área da amostra preenchida. Destas 14 amostras, $78,6 \%$ continham células epiteliais separadas, mais alongadas, de rel. N/C aproximada entre 1:3 e 1:5, bordas citoplasmáticas dobradas. Em apenas $21,4 \%$ (3 em 14), células caliciformes foram encontradas e exclusivamente no local em que havia feixe de células epiteliais coesas. Filamentos de muco e mucina estavam presentes em $100 \%$ do grupo. Células inflamatórias (neutrófilos) em secreção foram observadas em $57,1 \%$ dos casos. Em apenas uma amostra verificou-se presença de células inflamatórias intraepiteliais (TABELA).

TABELA 1 - COMPOSIÇÃO PERCENTUAL DOS TIPOS CELULARES, RELAÇÃO NÚCLEO/ CITOPLASMA E PRESENÇA DE MUCO. SÃO PAULO, 2004.

\begin{tabular}{cccc}
\hline & CÓRNEA & CONJUNTINA & TARSO \\
\hline Relação núcleo/ citoplasma & $1: 5$ & $1: 2-1: 7$ & $1: 3-1: 5$ \\
Células epiteliais separadas & $92,3 \%$ & $87,2 \%$ & $78,6 \%$ \\
Células caliciformes & $0 \%$ & $0 \%$ & $21,4 \%$ \\
Células inflamatórias & $10,3 \%$ & $50 \%$ & $57,1 \%$ \\
Alterações nucleares & $46,1 \%$ & $71,8 \%$ & $64 \%$ \\
Filamento de muco & $10,3 \%$ & $30,7 \%$ & $100 \%$ \\
Mucina & $0 \%$ & $15,4 \%$ & $100 \%$ \\
\hline
\end{tabular}

\section{Discussão}

O presente estudo definiu as características encontradas nas células superficiais das conjuntivas bulbar e tarsal e da córnea de olhos sadios de cães avaliados por citologia de impressão.

A padronização do corte e do formato do papel filtro e de sua colocação na córnea, conjuntiva bulbar e tarsal permitiu a identificação dessas áreas no momento da leitura da lâmina, facilitando assim a interpretação dos resultados. A distinção entre o epitélio conjuntival e o corneano é difícil baseando-se apenas no aspecto morfológico das células quando tem-se perda da coesão intercelular e aumento da área celular da conjuntiva (DOUGHTY, et al., 2000). Nas colheitas córneo-conjuntivais foi possível definir a diferença entre o material proveniente da córnea daquele da conjuntiva por meio da observação do corte do papel. Células da córnea localizaram-se da abertura lateral ao ápice, enquanto que células da conjuntiva encontraram-se da abertura lateral à base.

A colheita das amostras foi adequada mesmo 
nos cães acordados, utilizando-se apenas colírio anestésico. Sua instilação é necessária não apenas para diminuir o desconforto do animal como também para remoção de possíveis debris celulares da córnea que pudessem estar aderidos à conjuntiva bulbar (DOUGHTY et al., 2000). As regiões nasal e inferior mostraram-se inadequadas para a colheita de material da conjuntiva bulbar devido à presença da terceira pálpebra mesmo com o animal mantido sob anestesia geral.

A qualidade do material obtido foi considerada adequada para análise citológica, visto que a celularidade e a morfologia estavam de acordo com os parâmetros descritos em estudos prévios de padronização da técnica (TSENG, 1985; NELSON, 1988; GADKARI et al., 1992; MARTINEZ et al., 1995; BARROS et al., 2000; BARROS et al., 2001). A celularidade do tarso foi a menor provavelmente por tratarse de região que permite menor aderência das células no filtro e pela presença de material de secreção mucosa.

Além da biópsia excisional (KESSING, 1968; GREINER et al., 1981), estudos prévios mostraram que citologia de impressão de olhos normais de seres humanos tem como resultado a presença de células caliciformes na conjuntiva bulbar e tarsal em quantidades que variam de acordo com a região anatômica, com a presença de feixe de células epiteliais coesas pequenas com relação núcleo citoplasma de 1:1e 1:2 e formato levemente ovalado (TSENG, 1985; NELSON, 1988; GADKARI et al., 1992; MARTINEZ et al., 1995; BARROS et al., 2000; BARROS et al., 2001). Feixes de células epiteliais coesas são geralmente obtidos de conjuntivas sadias, porém, à medida que o ambiente celular sofre alterações, as células ficam mais separadas (KESSING, 1968; GREINER et al., 1981) e há importante redução ou ausência da população de células caliciformes (KINOSHITA et al., 1983; TSENG, 1985). A presença de células epiteliais separadas, mais alongadas, com citoplasma abundante, núcleos picnóticos ou ausentes e redução ou ausência das células caliciformes na citologia de impressão de seres humanos são características compatíveis com metaplasia escamosa conjuntival (NELSON e WRIGHT, 1984; TSENG, 1985). No presente estudo, as características do epitélio corneano e conjuntival dos animais avaliados foram compatíveis às observadas em pacientes humanos com metaplasia escamosa e perda de células caliciformes.

Nos resultados, o aspecto "metaplasia-like" e a ausência de células caliciformes detectada com a citologia de impressão da conjuntiva bulbar em todos os casos sugere que exista diferença no aspecto epitelial da conjuntiva bulbar do cão e do homem. Portanto, não é adequada a comparação de resultados citológicos envolvendo as duas espécies. A escassez ou ausência desse tipo celular nas regiões de conjuntiva bulbar canina já havia sido descrita (MOORE et al., 1987; BOLZAN, 2003), inclusive por meio de biópsia excisional de toda superfície da conjuntiva canina (MOORE et al., 1987). As células caliciformes são essencialmente ausentes nas áreas de conjuntiva bulbar, enquanto que no fórnice nasal inferior, fórnice medial inferior e tarso nasal inferior são encontradas as maiores densidades (MOORE et al., 1987).

A presença de células caliciformes conjuntivais detectada com a citologia de impressão neste estudo foi verificada exclusivamente no tarso e apenas em poucas amostras (3 em 14), nas quais foram encontrados feixes de células epiteliais coesas. Infelizmente, a qualidade das amostras obtidas com citologia de impressão do tarso de cães foi inadequada, com baixa celularidade, limitando a utilidade diagnóstica desse método. Além disso, a pesquisa da densidade de células caliciformes em áreas bulbares, embora usada em seres humanos, pode não servir como indicador de alteração da superfície ocular para a espécie canina. Estudos futuros são necessários para a identificação das características citológicas nas afecções da superfície ocular de cães.

\section{Conclusão}

A citologia de impressão é um método factível para avaliação da superfície ocular em cães. Entretanto, a celularidade nas amostras obtidas do tarso mostra-se inadequada e a pesquisa da densidade de células caliciformes em áreas bulbares, embora usada em seres humanos, 
Padronização da citologia de impressão da superfície ocular canina

pode não servir como indicador de alteração da superfície ocular para a espécie canina.

\section{Agradecimentos}

As acadêmicas Caroline Ribeiro e Helga da Silva pelo trabalho de coloração das amostras e montagem de todas as lâminas.

\section{REFERÊNCIAS}

BARROS, J.N.; MASCARO, V.L.D.M.; GOMES, J.A.P.; FREITAS, D.; HOFLING-LIMA, A.L. Citologia de impressão na avaliação da superfície ocular. In: XIV CONGRESSO DE PREVENÇÃO DA CEGUEIRA E REABILITAÇÃO VISUAL, 14., 2000. Anais... Natal, 2000. p.53.

BARROS, J.N.; MASCARO, V.L.D.M.; GOMES, J.A.P.; FREITAS, D.; HOFLING-LIMA, A.L. Citologia de impressão da superfície ocular: técnica de exame e coloração. Arquivos Brasileiros de Oftalmologia, São Paulo, v.64, p.127-31, 2001.

BOLZAN, A.A. Técnica de citologia conjuntival por impressão adaptada para o uso na espécie canina. Estudo experimental [tese]. Jaboticabal,2003. Universidade Estadual Paulista.

BOURNOUS, D.I.; KRENZER, K.; KASWAN, R.L.; HIRSH, S.G. Conjunctival impression cytology from dogs with keratoconjunctivitis sicca. In: SULLIVAN, A.A. et al. Lacrimal land, tear film and dry eye syndromes 2. New York: Plenum Press, 1998, p. 997-1000.

DART, J. Impression cytology of the ocular surface - research tool or routine clinical investigation. The British Journal of Ophthalmology, London, v.81, p.930, 1997.

DOUGHTY, M.J.; BLADES, K.; BUTTON, N.F.; WILSON, G. Further analysis of the size and shape of cells obtained by impression cytology from the exposed portion of the human bulbar conjunctiva. Ophthalmic \& Physiological Optics, Oxford, v.20, n.5, p.391-400, 2000.

EGBERT, P.R.; LAUBER, S.; MAURICE, D.M. A simple conjunctival biopsy. American Journal of Ophthalmology, v.84, p.798-801, 1977.
GADKARI, S.S.; ADRIANWALA, S.D.; PRAYAG, A.S.; KHILNANI, P.; MEHTA, N.J.; SHAHA, N.A. Conjunctival impression cytology - a study of normal conjunctiva. Journal of Postgraduate Medicine, Mimbar, v.38, p.21-3, 1992.

GREINER, V.J.; HERRIQUES, A.S.; COVINGTON, H.I.; WEIDMAN, T.A.; ALLANSMITH, M.R. Goblet cells of the human conjunctiva. Archives of Ophthalmology, Chicago, v.99, p.2190, 1981.

KESSING, S.V. Mucous gland system of the conjunctiva: a quantitative normal anatomic study. Acta Ophthalmologica, Copenhagen, v.95(suppl), p.9,1968.

KINOSHITA, S.; KIORPES, T.C.; FRIEND, J.; THOFT, R.A. Goblet cell density in ocular surface disease. A better indicator than tear mucin. Archives of Ophthalmology, Chicago, v.101, n.8, p.1284-7, 1983. MARTINEZ, A.J.; MILLS, M.B.; JACELDO, K.B.; TIO, F.O.; AIGBIVBALU, I.B.; HILSENBECK, S.B. et al. Standardization of conjunctival impression cytology. Cornea, Philadelphia, v.14, n.5, p.515-522, 1995.

MOORE, C.P.; WILSMAN, N.J.; NORDHEIM, E.V.; MAJORS, L.J.; COLLIER, L.L. Density and distribution of canine conjunctival goblet cells. Investigative Ophthalmology \& Visual Science, Bethesda, v.28, p.1925-32, 1987.

NELSON, J.D.; WRIGHT, J.C. Conjunctival goblet cell densities in ocular surface disorders. Archives of Ophthalmology, Chicago, v.102, p.1049-51, 1984.

NELSON, J.D. Impression cytology. Cornea, Philadelphia, v.7, p.71-81,1988.

ROCHA, N.S.; BURINI, C.H.P.; LIMA, L.S.A.; KAMEGASAWA, A.; OLIVEIRA, A.A.F. Citologia de impressão da conjuntiva ocular do homem e do cão. Revista Brasileira de Medicina Veterinária, v.24, n.2, p.58-60, 2002.

THIEL, M.A.; BOSSART, W.; BERNAUER, W. Improved impression cytology technique for the immunopathological diagnosis of superficial viral infections. The British Journal of Ophthalmology, London, v.81, p.984-8, 1997.

TSENG, S.C.G. Staging of conjunctival squamous metaplasia by impression cytology. Ophthalmology, Philadelphia, v.92, p.728-33, 1985.

Recebido para publicação: 30/01/2005 Aprovado: 